\title{
Global Organizational Innovation Strategy
}

\author{
Yezdi H. Godiwalla ${ }^{1}$ \\ ${ }^{1}$ Formerly of: Management Dept., College of Business and Economics, University of Wisconsin-Whitewater, USA \\ Correspondence: Yezdi H. Godiwalla, W283N3671 Yorkshire Trace, Pewaukee, WI 53072-3311, USA.
}

Received: June 29, 2018

Accepted: July 14, 2018

Available online: July 24, 2018

doi:10.11114/ijsss.v6i8.3477

URL: https://doi.org/10.11114/ijsss.v6i8.3477

\begin{abstract}
Global innovation strategy makes a global (or international) organization more competitive and contributes to long term growth. A focus on newer trends and approaches in the technology and internal and external organizational processes would help the innovative and entrepreneurial spirit and endeavor. The proper organizational entrepreneurial goals, strategy and culture would generate greater connectedness with the relevant task environments for the global organization to explore and subsequently pursue newer product and services. Altogether, the integrated global sharing, joint experimentation among its subsidiaries and their combined innovation effort, the well-interfaced global supply chain's innovative endeavors, and the well-planned and systematic innovation strategy, together would spur greater global competitiveness and growth. It is a combined global approach that would effectively generate innovation.
\end{abstract}

Keywords: international management, innovation in international business, global innovative strategy, organized innovation in global organizations

\section{Introduction}

George Bernard Shaw, the famous playwright, said, "The reasonable man adapts himself to world; the unreasonable one persists in trying to adapt the world to himself. Therefore, all progress depends on the unreasonable man". It is also in this same vein that Elkington and Hartington (2008) argue that being unreasonable is "a process by which older, outdated forms of reasoning are jettisoned and new ones conceived and evolved." They further said that just as the unreasonable bicycle makers, the Wright brothers, dreamed of flying like the birds, "today's social and environmental entrepreneurs see the possibility of helping people soar into the future where others see only insurmountable barrier", (Elkington \& Hartington, 2008). Innovation is the realized dreams of unreasonable people. The unreasonable people move the situation to suit their vision. They create a sense of challenge for themselves and others and even inject uncertainty and chaos to affect innovative changes which only their acumen guides through.

Thomas Edison's innovation is legendary. His five competencies of innovation are: "(1) Solution-centered mindset, (2) Kaleidoscopic thinking, (3) Full-spectrum engagement, (4) Master-mind collaboration, and (5) Super-value creation." (Gelb \& Caldicott, 2007). His innovation process is widely accepted as the template for successful innovation and it is widely used by many other innovators. Innovation is a process which is fraught with uncertainty and is fueled by persistent creativity.

Stability and instability within an organization are the twin sources of short and long term operational performance. Stability within an organization provides certainty and predictability, which in turn provide the productive use of current resources. Instability provides uncertainty and chaos, which in turn provide opportunities for innovation and creative problem-solving. It is the latter that ensures the effective future organizational performance. This tenet, that is to say, uncertainty induces innovation, is particularly true for organizations facing uncertainty emanating from innovation and competitive challenges. Strategic orientation by its very nature is future and external in its orientation. It espouses the concept that organizations have the compelling need to adapt their internal configurations of resources, culture, tasks, technologies and structure to the external challenges and changes. Strategic innovation focuses on preparing the organization for meeting the future challenges through effective innovation. Innovations, when meaningful, are the hallmarks of successful organizations.

Innovations, when meaningful, are also the hallmarks of successful civilizations. Innovations, when meaningful, have improved the lives of mankind. It has uplifted the people from their struggling plights and save them from drowning in helpless drudgery. Innovations bring about significant economic vitality and they have improved the quality of life and 
standard of living to the people who give and receive the rewards of innovation. The transfer of innovation across the world brings about immense revolution of ideas, products and services, knowledge and technical applications (Afuah, 2003; Govindarajan \& Trimble, 2005). They spur economic growth and increase gainful employment, provide new income streams, revitalize employees in organizations and refresh their value chain members with renewed sense of purposes, and, provide the customers and users of the innovations with better quality of life, often providing newer sources of satisfying needs which were hitherto undiscovered. Innovations in organizations often imply technological innovations and, additionally, they also can include using the existing technology and innovate the delivery or application process in ways that added convenience would further customer convenience and satisfaction.

In the face of immense competition, faster customer preference changes and fast paced technical growth and changes, global organizations would benefit by creating an adaptive and high performance organizational culture and process for increased competitiveness to sustain better market shares and profits (Greco, Grimaldi \& Cricelli, 2016). For these purposes of growth and competitive advantages, global organizations may benefit by developing a committed and comprehensive global innovation strategy. Innovative culture should be the central value of the organizational culture, marked by high critical thinking as well as high creative thinking. One regards working in an organization not only as a source of livelihood but also as a way life. And, innovation, critical thinking and creative thinking must become the central way of life over and above the performance of the routine operating activities (Afuah, 2003; Schilling, 2008; White \& Bruton, 2011). This approach would combine the creative and operational activities together work for the short and long term performance of the global organization. Innovation serves the twin born goals of organizational growth and competitiveness. Sustained performance of a global organization in a world marketplace depends on its ability to blend the operation performance with the emerging promise of innovation for future entries of organizational outputs of products and services of marketplace relevance ( $\mathrm{Lu}$ et al, 2017). Innovation should be made not only become the catch word in the global organization, but it must also be kept up as the ever burgeoning spirit of entrepreneurial creativity and innovation. The goals for innovation goals and the spirit of creativity and innovation should be inculcated in the people of the global organization for energizing the competitiveness and growth.

Global or international organizations would benefit by pursuing a comprehensive global strategy of continuous innovation which would engender sustained future improved competitiveness and sustained growth. These are better pursued through looking beyond the daily, weekly and monthly operational activities and by seeking newer approaches and experimenting with them. Both approaches should be simultaneously pursued. An organic rather than a mechanistic approach would create the creative organizational culture so conducive to innovation and exploring and evaluating newer ideas in an entrepreneurial manner.

\section{The Purpose of the Paper}

This paper deals with ideas for innovation strategies for a global organization for its improved competitiveness and sustained growth. The paper presents ideas for global innovation strategy for this purpose. A global organization, with its headquarters (HQ), its various regional headquarters, if any, and their foreign subsidiaries, must function jointly and collectively in order to effectively innovate. The spirit of organizational innovation and renewal should be viewed as an on-going continuous activity for the purpose of meeting the challenges arising out of competition, market changes, and technological advances. Thus, growth and profitability are organizational goals that are better sustained through innovative and entrepreneurial endeavors.

\section{International Innovation Strategies for Success}

The foreign subsidiaries of a global or international organization can become major engines of effective innovation. Philips of The Netherlands has most of its innovation performed by its foreign subsidiaries. The challenge of becoming increasingly more international is to nurture newer, more useful ideas which may sprout from anywhere in the organization. These burgeoning ideas may come up from unexpected quarters as well. These creative ideas can be seemingly humble and unimportant; however, once they are viewed collectively, they can affect significant and substantial competitive advantage. For example, BMW kept on improving many smaller items and attributes in its cars year-after-year until it was recognized to be stellar performer.

There can be an opinion that HQ and foreign subsidiaries jointly can perform effective innovation. This is quite different from the notion that innovation is centrally performed by the HQ and these innovations are passed down to the foreign subsidiaries. Growth-oriented innovation ideas are often generated by foreign subsidiary units (Birkinshaw, 1999; Birkinshaw, 2001; Govindarajan \& Trimble, 2005). Because a global organization's foreign subsidiaries can be in far flung theaters of the organizational environment, each foreign subsidiary can focus upon its specific host country needs and develop newer strategies to meet with emerging demands and challenges emanating from the host country environments. 


\section{Models of Relationships Among: Headquarters, Business Units and Foreign Subsidiaries}

Dealing with business units and foreign subsidiary units is an important organizational relationships issue. The global organizational HQ must foster the cooperative spirit among the business units and foreign subsidiary units so that the combined partnership improves innovation and the effective dealing with long term innovation challenges and needs (Birkinshaw, 1999; Birkinshaw, 2001; Gates, 1996; Roth \& Morrison, 1992). The three major ways for a global organization's HQ relationship style (in dealing with the global organization's foreign subsidiary units) are:

1. The Headquarters of the Global Organization's top-down management style: The global (or international) organization makes most of the important decisions almost unilaterally and hierarchically dictates the foreign subsidiaries to follow them (Gates \& Engelhoff,. 1986).

2. Rapid Growth and Expansion Approach: This approach has the following three alternatives methods and many global organizations resort to them, varying them as needed (Chan \& Mauborgne, 1993):

(a) Headquarters-driven transfer to the foreign subsidiary units of resources: capital, human, technological, and intangible resources: This approach focuses on a highly-resourced headquarters so that they can dominate the resource build up for the foreign subsidiaries. The transfer of resources provides leverage to the headquarter expansion and growth activities of the foreign subsidiaries (Frenkel, 1998). Such transfers stimulate rapid growth of the foreign subsidiaries, a measure that can help a first or the second mover to consolidate its market standing in the subsidiary's country and region.

(b) Foreign subsidiary obtains resources from its local sub-environments so that it is less dependent on the headquarters for growth and expansion: In this non-dependence model, the foreign subsidiary develops its own goals and plans for growth and expansion so long as it does within the broad scope of the global headquarters' vision. Their credibility and reputation allow it to seek local capital, technology, human resources, and organizational support to pursue its growth and expansion, using the same or different products, technologies, businesses, or markets (O’Donnell, 2000).

(c) Some combination of the above (a) and (b): The foreign subsidiary may use varying mixes of the two methods (a) and (b) as it finds it useful, flexible and viable for growth and expansion, with or without diversification. It may be that this hybrid model of local growth would facilitate rapid and untrammeled local growth and expansion.

3. Combination Model: The global headquarters and the foreign subsidiary combined develop growth and expansion plans and collaborate closely for the foreign subsidiary's local expansion (Roth \& Morrison, 1992). . Often the approach is marked by frequent and close communication and systematic step-by-step approach in planning and implementing the growth processes. Repeated cycles of combined growth approaches bring the two entities closer.

\section{A Systematic Innovation Process}

The literature on Thomas Edison's innovation process cites five steps, involving a "solution-centered mindset" (Gelb and Caldicott, 2007, 47-48). They are: "(1) Align Your Goals with Your Passion, (2) Cultivate Charismatic Optimism, (3) Seek Knowledge Relentlessly, (4) Experiment Persistently, and (5) Pursue Rigorous Objectively”. These five steps are believed to be effective in facilitating the innovation process in ways that appear to be both disciplined and creative. They keep the process moving along and foster creativity in a focused way. The "solution-centered mindset" approach in this process is supposed to loosen oneself and set oneself free and seek a better approach going forward. This approach fosters a creative and an open mind seeking ideas along a path centered for meaningful innovation. Thus, the approach, while flexible in its ways, is also broadly goal-oriented. The global organization must follow the simultaneous approach of flexibility and broad goal orientation as it orchestrates innovative processes in the global organization.

The global organization's headquarters should nurture the foreign subsidiaries. They can try different subsidiaries to test and develop different ideas, projects, business, technological or product development. With these kinds of options, the headquarters can nurture its foreign subsidiaries to experiment with newer approaches to suit local conditions and needs. They can try entrepreneurial ventures, enact newer markets, develop more locally suitable technologies, operational processes, and seek local collaborations ( $\mathrm{Lu}$ et al 2017; O’Donnell, 2000)). Such initiatives can be viewed as tentative, but in the long run it is beneficial for a foreign subsidiary to become more self-reliant in its efforts to become more entrepreneurial and locally adapted (Chan and Mauborgne, 1993).

\section{The Models for the Global Organizational Innovation Strategy}

There are four exhibits and these are discussed here. Here is a summary of the contents of the exhibits: Exhibit 1 presents a model for global organization's global strategy and innovation strategy, and suggests the use of gap analyses for this purpose. Exhibit 2 provides the innovation process through analyses of the environmental scanning process in 
the use of strategic management process. Exhibit 3 provides the three cycles, nine step process of the global organizational innovation, emphasizing a systematic planned approach. Exhibit 4 suggests ways to implement innovation as a regular part of organizational process. The four exhibits provide an integrated and comprehensive picture of the organization-wide systematic approach to innovation in a global organization.

\subsection{Exhibit 1: The Formulation Process for Global Organizational Innovation Strategy}

Exhibit 1 portrays the relationship between global corporate strategy and innovation strategy. The organization's global corporate goals and strategy provides specific indications about the global organization's innovation goals and strategies. The global organization's strategic management process would raise issues of external environmental challenges and provide focus upon the projected gap or deficit in organizational performance.

The performance deficit or gap analyses, which are intended to specify the details of resource deficit in the context of the challenge, would raise considerations at the overall global organizational level, regional level, and foreign subsidiary unit level. These performance deficit or gap issues may include topics such as product development and improvement, organizational process improvements, customer service improvements, marketing innovations, enactment of new regions for the global organization's markets, re-focusing on organizational primary purpose in view of changing environments.

At the global organizational level, the overall organizational innovation processes would include: global product-market offerings, organizational re-structuring to better serve constituent markets, improved services to generate better organizational support for its foreign units for such activities as technical support, R\&D, advertising, marketing, logistics, product adaptation, product re-design, and process re-design.

At the regional level, the focus should be for better coordination of its foreign subsidiaries' activities as they can be better synthesized where such synthesis would build strengths through synergy, organizational learning and experience, marketing intelligence, and technical problem solving.

At the foreign subsidiary's level, the focus is on effective adaptation to the local environment (Roth \& Morrison, 1992). Such adaptation requires continuous refining and innovation through organizational renewal and tuning with the local culture. The foreign units' innovative activities may include: adaption to local supplier conditions, local technical constraints, local labor market conditions, local infrastructural constraints, and local market needs for the global organization's products and services.

To conclude, the foregoing would lead to the scope, intent and depth of innovation strategies. Growth and profitability are the more common motives of innovation. In addition, a common denominator for driving innovation is the challenge emanating from the external environment, notably competitive challenge and changing and rising customer expectations. Often, internal environment can spur innovative endeavors, such as creative and innovative aspirations of the people. Innovative spirit can be nurtured through a creative culture of the people of the organization.

\subsection{Exhibit 2: The Global Organizational Goals, Innovation Needs Analysis, and, the Comprehensive Innovation Goals and Plans}

Exhibit 2 depicts the process of analyses and assessment of environmental trends, and organizational goals and capabilities. The top managements of the global organizational HQ, regions, and foreign subsidiary units must continuously scan their respective strategic external environments as they reassess the future needs. In the analyzing of patterns of environmental changes, a global organization (at all the three units of analysis: the global organizational HQ, regions, and foreign subsidiaries' top managements) determines the competitor analyses and consequently assesses its innovation needs for the future.

For the global organizational, innovation directions are determined by the plans to cope or proactively change the undesirable aspects of the future states of external environments. The anticipated future states of external environments often make the need for an organic global organizational focus upon a strategic approach to prepare ahead and manage change effectively. In doing so, the global organization has to pursue innovative activities to meet the anticipated challenges.

The future global organizational goals would focus upon the global organizational resource development plans. In the on-going global organizational resource development process, innovation and strategic responses must feature in future innovation processes.

The global organizational innovation and growth plans would be integral parts of the global organizational global strategies. Innovation is often viewed as a means to accomplish long term global organizational goals and achieve increased competitiveness.

To conclude, for the global organizational, innovation must be considered as a strategy, a strategy to further the global 
organizational goal accomplishment process. Ideas of innovation thus must be viewed as ideas that are founded in the internal and external environments, such as: competitor challenges, technological advancements, creative desires of the organizational peoples, and competitive pressures.

\subsection{Exhibit 3: A Model for a Systematic Process of Organizational Innovation: Three Phases and Nine Steps}

Exhibit 3 portrays the continuous process of nine steps of innovation. The continuous process is broken into three phases as they identify three distinct challenges, determine goals, plan for effective innovation to meet with external and internal needs, identify resources needed, and the implementation of the innovation strategy. The three phases and the nine steps are described here:

Phase 1: Identify innovation goals and skills: The trends in the external events would give enough cues to the top management to develop a profile of the external challenges and the scope and content of desired problem solving innovation. This step-by-step approach is similar to the on often used in management control systems. It has three phases and nine steps, three steps in each of the three phases:

Step1. The initial step is to identify the future global challenges and to generate a culture and climate to identify areas of sub-par performance, or, external global threat areas which need to be addressed by the overall global organizational HQ.

Step 2. The regions should focus upon the regional challenges and develop regional innovation goals to foster growth and development of the foreign units within the region.

Step 3. Each foreign unit should focus on its host country's challenges and needs and should develop unit-specific innovation goals and plans.

Phase 2: Formulate innovation strategy, plans and identify resources: The second cycle should focus upon strategies and plans to accomplish the innovation goals to solve the impending problems.

Step 4. Define in greater detail and specificity the goals of innovation, and formulate strategy to focus upon innovation for all scopes: the overall global organizational, regions and foreign units.

Step 5. The organization of regional activities and services of all foreign units within the region should be planned and coordinated in this step.

Step 6. Finalize detailed plans for each foreign unit to organize innovative activities.

Phase 3: Finalize the details of Implementation:

Step 7. Global coordination plans for innovation should be formulated for the overall global organization. Growth plans must be integrated in this approach.

Step 8. At the regional level, the focus should be to organize innovation details and activities for generating effectiveness.

Step 9. Perform innovation activities. Implement innovation strategies. Improve innovation effectiveness to better achieve corporate goals.

To conclude, innovation should be a systematic activity that is well organized and institutionalized. Focus should be upon the results of innovation as it fosters better working culture and results. Competitiveness, market share, profitability and organizational growth should be achieved through a continuous process of organizational renewal.

6.4 Exhibit 4: A Model for the Process of Institutionalizing Innovation at All Levels of the Global Organization: Global $H Q$, Regional HQ, and Foreign Subsidiary Units

The attributes of an innovative organization should continuously focus upon critical thinking, brain-storming for ideas for growth, and, the culture should be to nurture talents, skills and resources that are conducive to creative and innovative activities (Chan \& Mauborgne. 1993).

The emphasis of the exhibit is to generate enough innovative knowledge, resources and skills and to provide better growth, competitiveness and competitiveness in the market place. Organization-wise, the innovation process would be the emphasis of those who spearhead the change. The innovation is tested for possible inconsistencies and impracticalities. After the potential faults are removed, the innovation is implemented more fully into the system of the organization. Then the regularity of the administrative process, together with the innovation incorporated into the system, would influence the organizational culture and future process.

This process should be pursued at all levels: the global organizational HQ, regional HQ and foreign subsidiary units. Further, there should be coordination and continuity of purpose and process among the three, the global organizational $\mathrm{HQ}$, regional $\mathrm{HQ}$, and foreign subsidiaries. 
The exhibit suggests that at each of the three levels, the global organizational HQ, regional HQ and foreign subsidiary unit, innovation is the key to continued success and competitiveness of the global organization. Innovation, incremental or radical, may be focused and applied to result in tangible benefits to the global organization. It may be first tested and evaluated for viability and worthwhileness. This is done through continual or periodical testing and refining until it is most in tune with reality. It should be operationalized and repeatedly refined until it is institutionalized.

To conclude, innovation may be fostered through four approaches: a) the global organizational HQ providing seed money, b) use formal requests for future project proposals, c) encourage the units to nurture new ideas, and d) forge strong inter-unit networks (Birkinshaw, 2001; Schilling, 2008)). The flow of activities in the exhibit provides the guidelines for the successful innovation process along a well -directed path. Innovation comes from deliberate and conscientious planning and organizational learning such that the strategic leadership visualizes the innovation vision and relentlessly pursues it.

\section{Conclusions}

Global innovation strategy is a central pillar of overall corporate strategy of a global organization. It has the potential to invigorate the long term, global organizational competitiveness profitability and performance (Schilling, 2008). Global growth and product-market expansion, technological superiority, competitive advantage, financial performances are some of the fruits of an effective innovation strategy.

The pursuit of a well-conceived and planned global innovation strategy requires sound global innovation vision; systematic innovation plans, well integrated global implementation time table and structure of implementation activities, and organized approach to implementation endeavor. Global innovation strategy should be an integral part of a comprehensive global organizational strategy. It should be involving all levels of the global organization: global HQ, business divisions, regional $\mathrm{HQ}$, and foreign subsidiaries in all its comprehensive, coordinated preparation and implementation.

Innovation takes determination, grit, creativity, capacity to take on uncertainty, and, also, very importantly, the "unreasonableness" quality of "the unreasonable man" about which George Bernard Shaw, and, John Elkington \& Pamela Hartigan ((2008) talked. The successive waves of innovation that the civilization has witnessed and benefitted have taken place are those that have mostly been achieved by the daring risk takers and entrepreneurs and the mavericks, and, by those who could think outside the box and off the wall. They did so in ways that others did not dare to take the risk nor had the imagination to even attempt to do so, let alone timidly, tentatively trying the path. They had the passion and the tenacity, the unwavering conviction, romance and obsession of their ideas and the desire to make a difference for the betterment of mankind.

\section{References}

Afuah, A. (2003). Innovation management: Strategies, implementation, and profits. New York, NY: Oxford University Press.

Birkinshaw, J. (1999). The determinants and consequences of subsidiary initiative in multinational corporations. Entrepreneurship Theory and Practice, Fall, 24(10), 9-52. https://doi.org/10.1177/104225879902400102

Birkinshaw, J. (2001). Unleash innovation in foreign subsidiaries. Harvard Business Review, March, 79(3), 131-140.

Chan, K., \& Mauborgne, R. (1993). Effectively conceiving and executing multinationals' worldwide strategies. Journal of International Business Studies, 24(3), 419-450. https://doi.org/10.1057/palgrave.jibs.8490239

Elkington, J., \& Hartigan, P. (2008). The power of unreasonable people: How social entrepreneurs create markets that change the world. Boston, MA: Harvard Business Press.

Frenkel, S. J. (1998). Corporate-subsidiary relations, local contexts and workplace change in global corporations. Industrial Relations, 53(1), 154-181. https://doi.org/10.7202/005277ar

Gates, S., \& Engelhoff, W. (1986). Centralization in headquarters-subsidiary relationships. Journal of International Business Studies, Summer, 17(2), 71-93. https://doi.org/10.1057/palgrave.jibs.8490425

Gelg, M. J., \& Caldicott, S. M. (2007). Innovate Like Edison: The Success System of America's Greatest Inventor. New York, NY: Dutton, Penguin Group (USA).

Govindarajan, V., \& Trimble, C. (2005). 10 rules for strategic innovation: From idea to execution. Boston, MA: Harvard Business School Press.

Greco, M., Grimaldi, M., \& Cricelli, L. (2016). An analysis of the open innovation effect on firm performance. European Management Journal, 34(5), 501-516. https://doi.org/10.1016/j.emj.2016.02.008

Lu, J. G., Hafenbrack, A. C., Eastwick, P. W., Wang, D. J., Maddux, W. W., \& Galinsky, A. D. (2017). "Going out” of the 
box: Close intercultural friendships and romantic relationships spark creativity, workplace innovation and entrepreneurship. Journal of Applied Psychology, July, 102(7), 1091-1108. https://doi.org/10.1037/ap10000212

O'Donnell, S. W. (2000). Managing foreign subsidiaries: Agents of headquarters, or an independent network? Strategic Management Journal, 21, 525-548.

https://doi.org/10.1002/(SICI)1097-0266(200005)21:5<525::AID-SMJ104>3.0.CO;2-Q

Roth, K., \& Morrison, A. (1992). Implementing global strategy: Characteristics of global subsidiary mandates. Journal of International Business Studies, 23(4), 715-750. https://doi.org/10.1057/palgrave.jibs.8490285

Schilling, M. A. (2008). Strategic management of technological innovation. New York, NY: Mc-Graw-Hill/Irwin.

White, M. A., \& Bruton, G. D. (2011). The management of technological and innovation: A strategic approach. Mason, OH: South-Western, Cengage Learning.

Exhibit 1. The Formulation Process for Global Organizational Innovation Strategy

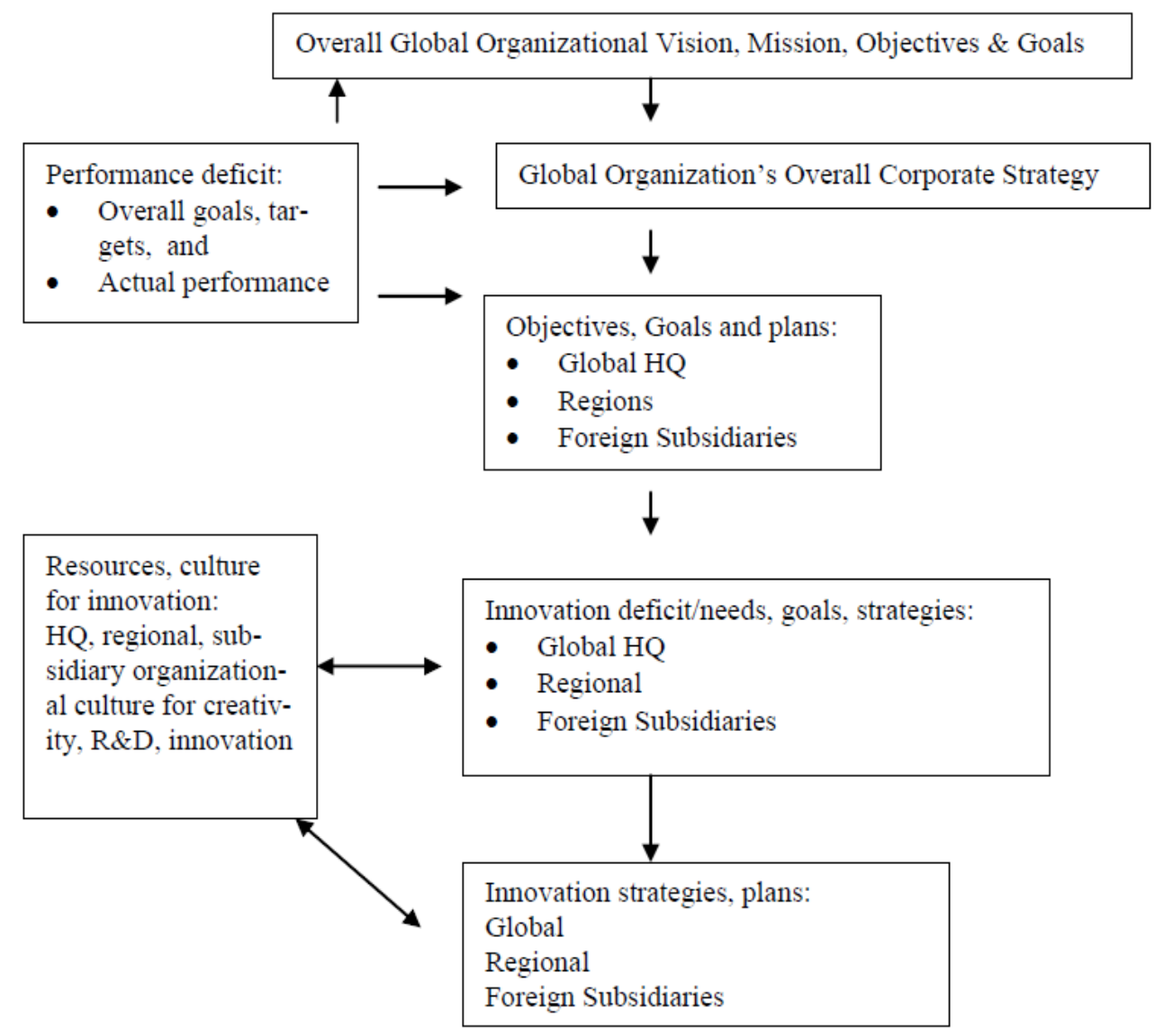

Exhibit 1. Description: As shown in Exhibit 1, the formulation process has a distinct flow process such that it would stimulate and provide a more systematic and orderly series of activities 
Exhibit 2. Global Organizational Goals, Innovation Needs Analyses, and, Comprehensive Innovation Goals, Plans

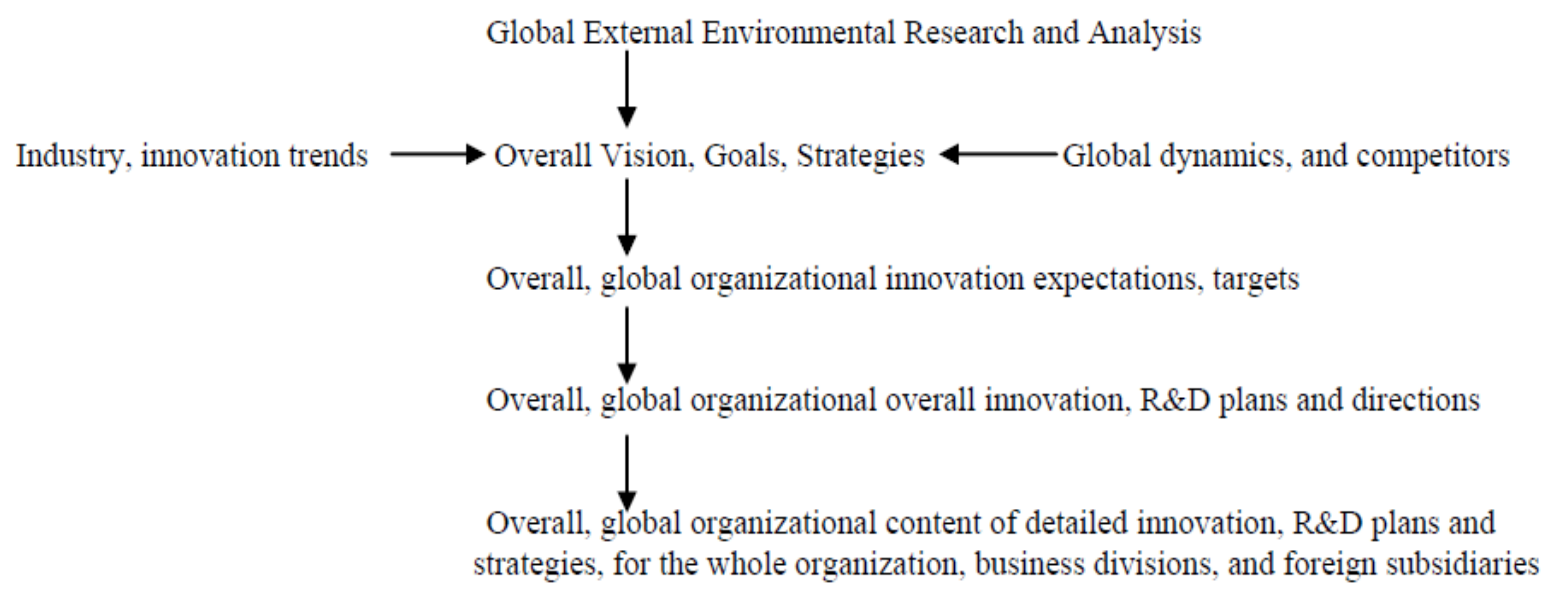

Exhibit 2. Description: As shown in Exhibit 2, the global organization's overall innovation goals and directions are predicated by its environmental factors and its own goals and objectives and overall corporate strategy

Exhibit 3. A Model for a Systematic Process of Global Organizational Innovation: The three Phases and Nine Steps

\begin{tabular}{|c|c|c|c|}
\hline & Phase 1 & Phase 2 & Phase 3 \\
\hline Primary Emphasis: & $\begin{array}{l}\text { Clear determination of the } \\
\text { innovation } \\
\text { objectives and the resources } \\
\text { needed }\end{array}$ & $\begin{array}{l}\text { Define the major details of } \\
\text { innovation projects across the } \\
\text { global organization. Identify } \\
\text { the responsibility centers of } \\
\text { the projects in business } \\
\text { divisions, regional offices, } \\
\text { and foreign subsidiaries. Set } \\
\text { up coordinating plans and }\end{array}$ & $\begin{array}{l}\text { Determine detailed operational } \\
\text { plans for effective } \\
\text { implementation of innovation } \\
\text { processes across the } \\
\text { organization. Establish } \\
\text { time-table of activities for } \\
\text { performing innovation. }\end{array}$ \\
\hline
\end{tabular}

Role of the Global HQ:

Role of the Regional HQ:
Step 1. Define the broad parameters of innovation needs and discuss the future innovation challenges likely to come before the overall organization. Coordinate the discussions. Provide information. Establish the innovation situation. Generate problem-solving approaches. Create broad picture of desirable innovation outcomes. innovation expectations and challenges. Identify additio data, skills and resource need Provide constructive approache for effective innovation within the region. up coordinating plans and monitoring processes.

Step 4. Finalize detailed
plans and programs for effectively implementing the innovation processes. Provide insourced/outsourced support for skills, knowledge and equipment and working capital for the innovation process. Develop effective coordination and monitoring process among all business divisions regions.

Step 5. Organize regional units' resources. Develop coordination processes of innovate programs among business divisions and foreign subsidiaries.

然

Step 7. Overall organizational integration and coordination of innovation activities and detailed program for effective performance of innovation. Establish metrics of performance of innovation activities Evaluate and correct the performance continually. Set yardsticks and provide for additional resources for improving effectiveness of innovation.

Step 8. Improve detailed activities and operationalize the network of intra- and interregional cooperation for better innovation effectiveness. Perform better nurturing and coaching of the divisions and foreign subsidiaries for better performance of innovation.

$\begin{array}{llll}\text { Step 6. Finalize } & \text { detailed } & \text { Step 9. Perform all innovation } \\ \text { innovation plans. } & \text { Identify } & \text { activities. Evaluate the } \\ \text { innovation project teams. } & \text { effectiveness of performance. }\end{array}$

Focus on post-innovation implementation preparations.

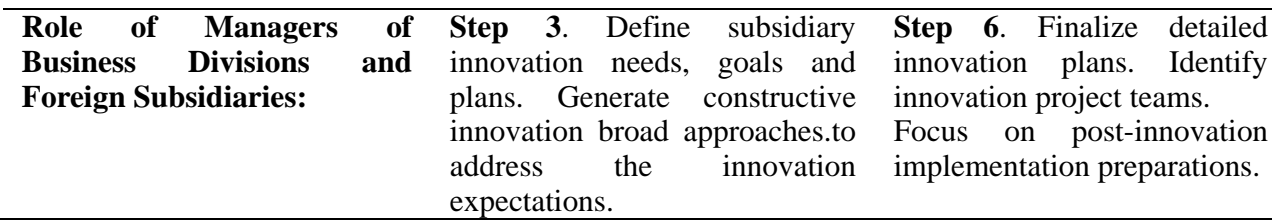

Exhibit 3 Description: As shown in Exhibit 3, the systematic global, organization-wide innovation process is a broadly structured and organized process. It has distinct three phases and then it also has nine specific steps. 
Exhibit 4. A Model for the Process of Institutionalizing Innovation at all Levels of a Global Organization: Global Headquarters, Regional Headquarters, and Foreign Subsidiary Units

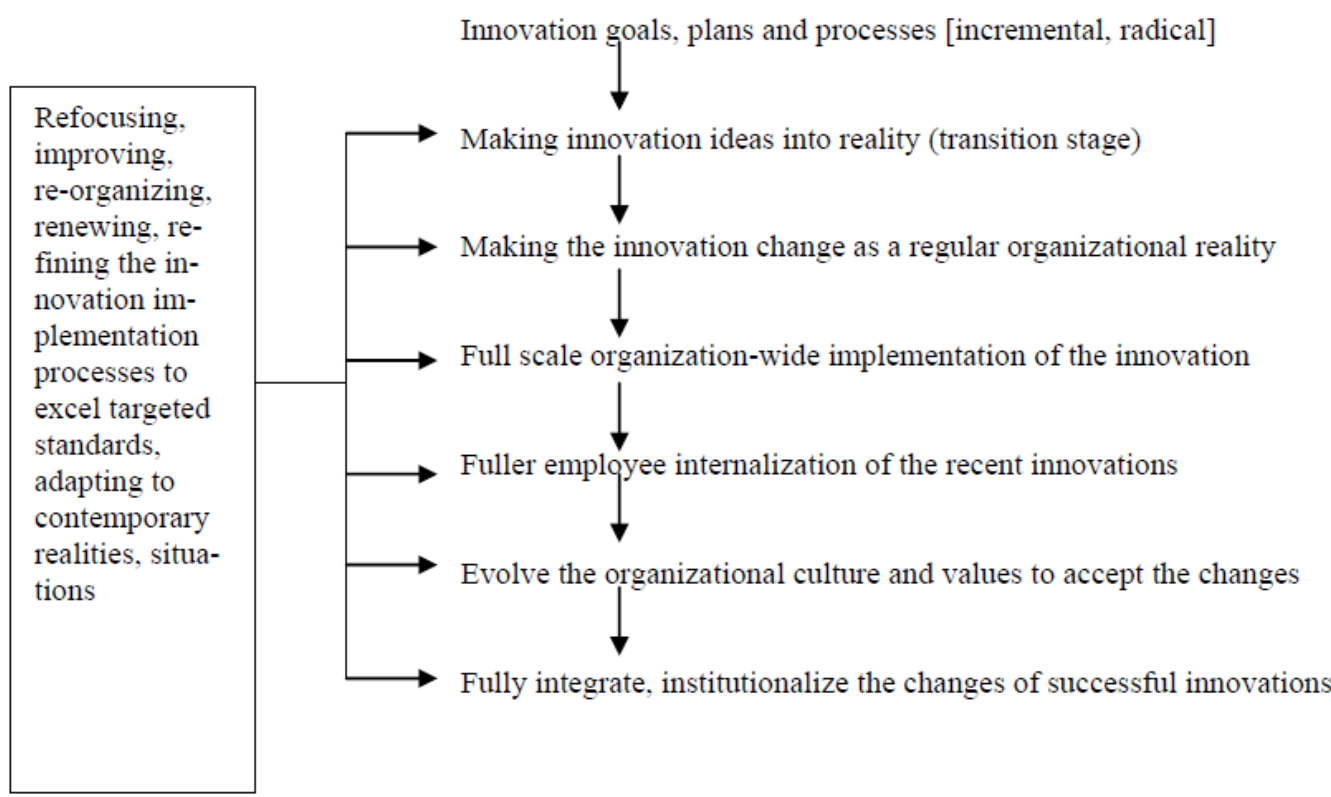

Exhibit 4 Description: As shown in Exhibit 4, it is through the process described in the above Exhibit, the effective institutionalization of innovative spirit and activities have to be melded so that the innovation capability remains vibrant, fresh and alive. The effective methods of innovation should be made permanent and the ineffective methods should be discarded as the organization strives to synthesize organization-wide the comprehensive innovation process.

\section{Copyrights}

Copyright for this article is retained by the author(s), with first publication rights granted to the journal.

This is an open-access article distributed under the terms and conditions of the Creative Commons Attribution license which permits unrestricted use, distribution, and reproduction in any medium, provided the original work is properly cited. 